\title{
Commentary
}

\section{How calorie-focused thinking about obesity and related diseases may mislead and harm public health. An alternative}

\author{
Sean C Lucan ${ }^{1, *}$ and James J DiNicolantonio ${ }^{2}$ \\ 'Department of Family and Social Medicine, Albert Einstein College of Medicine/Montefiore Medical Center, \\ 1300 Morris Park Avenue, Block Building, Room 410, Bronx, NY 10461, USA: ${ }^{2}$ Department of Preventive \\ Cardiology, Mid America Heart Institute at Saint Luke's Hospital, Kansas City, MO, USA
}

Submitted 29 May 2014: Final revision received 2 October 2014: Accepted 3 October 2014: First published online 24 November 2014

\begin{abstract}
Prevailing thinking about obesity and related diseases holds that quantifying calories should be a principal concern and target for intervention. Part of this thinking is that consumed calories - regardless of their sources - are equivalent; i.e. 'a calorie is a calorie'. The present commentary discusses various problems with the idea that 'a calorie is a calorie' and with a primarily quantitative focus on food calories. Instead, the authors argue for a greater qualitative focus on the sources of calories consumed (i.e. a greater focus on types of foods) and on the metabolic changes that result from consuming foods of different types. In particular, the authors consider how calorie-focused thinking is inherently biased against high-fat foods, many of which may be protective against obesity and related diseases, and supportive of starchy and sugary replacements, which are likely detrimental. Shifting the focus to qualitative food distinctions, a central argument of the paper is that obesity and related diseases are problems due largely to food-induced physiology (e.g. neurohormonal pathways) not addressable through arithmetic dieting (i.e. calorie counting). The paper considers potential harms of public health initiatives framed around calorie balance sheets targeting 'calories in' and/or 'calories out' - that reinforce messages of overeating and inactivity as underlying causes, rather than intermediate effects, of obesity. Finally, the paper concludes that public health should work primarily to support the consumption of whole foods that help protect against obesity-promoting energy imbalance and metabolic dysfunction and not continue to promote caloriedirected messages that may create and blame victims and possibly exacerbate epidemics of obesity and related diseases.
\end{abstract}

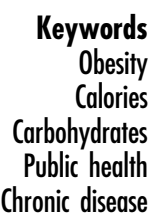

Keywords

Obesity

Calories

Public health

Chronic disease
With worldwide concerns about obesity and diseases related to it (e.g. diabetes and CVD), there is substantial interest in shifting populations to healthier weights and better health. More precisely, there is interest in reducing body fat since fat - particularly visceral or abdominal fat - may matter more than weight when it comes to health ${ }^{(1-3)}$. Nevertheless, much of the evidence regarding obesity and related diseases focuses on body weight, rather than body fat. In reviewing such evidence, therefore, the present paper will therefore also often use the imprecise term 'weight' as opposed to 'fat', pointing out when such imprecision might mislead thinking.
One way such imprecision might mislead thinking is in supporting the notions that (i) 'a calorie is a calorie' $\uparrow$ and (ii) intervening on calories is the best way to address obesity (i.e. the quantitative problem of excess pounds or kilograms on a scale as opposed to the qualitative problem

\footnotetext{
$\dagger$ 'Calorie' - or more correctly kilocalorie (kcal), for which the word often imprecisely substitutes - is the main unit of energy used to discuss food and obesity-related issues in the USA. It is also the word used in common expressions like 'a calorie is a calorie'. The word appears throughout this commentary as the energy unit of choice, but readers should feel free to substitute all instances with their own preferred energy unit; e.g. the joule (or the kilojoule or megajoule). No mathematical conversions are required as arguments are abstract and do not rely on specific quantities.
} 
of altered body metabolism). The two calorie notions are largely about balance sheets, essentially considering calories like units of body weight and units of body weight like inverse units of health; according to the logic, obese individuals need only try to consume fewer calories than they burn and they will achieve healthier weights and better health.

Although such logic is intuitive and enticing, reality is not quite so simple and existing evidence challenges calorie-focused notions. A view focused more on food quality, rather than caloric quantity, may help better explain and better address the growing problems of excess weight - or more precisely excess fat - and related conditions. Conversely, messages and initiatives based on the idea of calorie equivalency (that a 'calorie is a calorie') and interventions directed at calorie balance sheets may make these problems worse. The present paper reviews various problems with calorie-focused thinking, considers several advantages of 'more-nuanced thinking' (that considers calories principally as subordinate concerns to qualitative differences in food) and proposes an alternative path for public health to move forward.

\section{The problem with the idea of calorie equivalency}

A calorie is a unit of energy. As related to food energy, calories measure the potential energy a food could release. One calorie of potential energy equals one calorie of potential energy, just as one unit of anything equals another unit of that same anything. To say 'a calorie is a calorie' then is tantamount to the identity property in mathematics $(\mathrm{A}=\mathrm{A})$. As such, it is irrefutable.

In practice, however, the statement that 'a calorie is a calorie' often implies something different from mathematical identity. It implies that any two different foods, which have equivalent amounts of potential energy, will produce identical biological effects with regard to body weight/ body fatness when consumed. By this thinking, a calorie's worth of salmon, olive oil, white rice or vodka would each be equivalent and each expected to have the same implications for body weight and body fatness. Indeed, stating 'a calorie is a calorie' suggests that potential energy is the essential concern and that qualitative differences in the substances providing that energy are irrelevant.

But a calorie's worth of salmon (largely protein) and a calorie's worth of olive oil (purely fat) have very different biological effects from a calorie's worth of white rice (refined carbohydrate) or a calorie's worth of vodka (mostly alcohol) - particularly with regard to body weight/body fatness. Indeed, scientists have recognized differences in the weightrelated physiological effects of different calorie sources for more than half a century ${ }^{(4)}$. Although much early knowledge was based on animal studies, subsequent studies in human subjects have shown that calorie-providing proteins, fats, carbohydrates and alcohol each have substantially different effects on a variety of physiological pathways and hormones relevant to satiety, food consumption, weight maintenance and body composition: for example, different effects on ghrelin (an appetite-stimulating hormone), leptin (an appetite-suppressing hormone), glucagon (a hormone that raises blood sugar) and insulin (a hormone that lowers blood sugar) ${ }^{(5-7)}$.

The aforementioned descriptions of hormone activities are greatly oversimplified and the list of hormones far from exhaustive, but the examples serve to suggest that a given calorie's worth of salmon, olive oil, white rice or vodka might each behave quite differently in the body and produce different ultimate effects. Indeed, whereas some 'calories' (i.e. some amounts of different foods, quantified by their potential energy) induce metabolic pathways and hormones that squelch appetite and promote energy utilization, others stimulate pathways that promote hunger and energy storage. Even controlling for total calorie intake and energy expenditure from physical activity, qualitative differences in calories have different implications for obesity ${ }^{(8)}$; a calorie's worth of one food is not the same a calorie's worth of another ${ }^{(8-14)}$.

\section{Trying to intervene on calories is implausible and ineffective}

It follows from the problematic notion of calorie equivalency that any calorie consumed might be offset by a single calorie expended. Thus individuals wishing to lose weight should simply consume fewer calories than they expend. In other words, individuals should intervene on caloric quantity by consciously trying to 'eat less' and 'move more' than they otherwise would to establish 'caloric deficit' or 'negative energy balance, ${ }^{,(15)}$.

The problem with trying to 'eat less' and 'move more' to achieve - and more importantly, maintain - caloric deficit or negative energy balance is that it is practically and biologically implausible. Practically, even the most motivated, informed and knowledgeable individuals are unlikely to be able to estimate their actual calorie intake (not just ingested, informed by misleading food labels ${ }^{(16,17)}$, but absorbed $^{(18,19)}$ ) or their actual calorie expenditure (not just in physical activity ${ }^{(20)}$ but in variably efficient, silent and constantly fluctuating digestive and metabolic processes $\left.^{(12,14,18,21)}\right)$ and do so with sufficient accuracy and precision to maintain any kind of useful real-time calorie balance sheets. Biologically, calorie intake and calorie expenditure are coupled ${ }^{(22-26)}$. Unless substantial uncoupling occurs, reducing calories consumed will necessarily result in a compensatory drive to reduce calories expended and vice versa ${ }^{(26-31)}$. For this reason, people who try underconsuming calories become tired (an expenditure compensation) and hungry (an intake compensation), and one reason they often fail to lose weight (or have unimpressive results) $(25,26,32,33)$ may be that resultant hunger, 
particularly an increased desire for high-calorie foods ${ }^{(25,26)}$, drives compensatory overconsumption ${ }^{(26,28,33)}$.

Of course, some individuals do succeed at sufficiently uncoupling energy balance (i.e. do expend more calories than they consume) and do lose weight. But saying that these individuals lose weight because they expend more calories than they consume is like saying that students are late for class because they arrive after the bell rings. Both statements are true, but neither is causal. The associations do not explain the 'why' (i.e. in the case of expending more calories than consumed, why the uncoupling occurred).

Calorie equivalency and calorie balance sheets cannot explain the 'why'; why some people succeed in eating less and/or moving more and lose weight while others fail and gain weight. Calorie-focused thinking does not tell us why some people achieve net burning or net storage of calories, or how it is entirely possible to lose weight (as lean mass) and still gain fat (i.e. become more obese). Calorie thinking also cannot account for the dynamic non-linear response of body weight to stable energy imbalances over time ${ }^{(13,34,35)}$. Likewise, calorie thinking does not address why obesityrelated metabolic abnormalities ${ }^{(36,37)}$ and adverse events of obesity-related diseases ${ }^{(38-40)}$ may both occur before there is any gain in weight ${ }^{(3,41)}$, why metabolic improvements may occur at stable weight ${ }^{(42)}$ or why obesity-related adverse events may not decline with weight loss ${ }^{(43)}$. Any explanation for obesity should provide insights into these observations.

\section{More-nuanced thinking about obesity and related diseases}

To understand another kind of thinking about obesity and related diseases - and why individuals may show metabolic changes associated with being overweight before any detectable weight gain occurs - it is useful to consider body fat. Body fat - particularly visceral or abdominal fat - is a complex tissue that plays critical roles in appetite stimulation, energy expenditure and weight regulation. Normally, when a body's fat cells are replete (i.e. full with stored fat), they release a hormone called leptin. Leptin stimulates parts of the brain to send additional hormone and nerve signals to the thyroid gland, skeletal muscles, heart, intestines and other fat cells ${ }^{(25,27)}$. These signals are to decrease energy intake (i.e. to 'eat less') and increase energy expenditure (e.g. to 'move more') ${ }^{(27,29)}$.

As individuals start to become obese, however (metabolically speaking, if not yet by weight on a scale), something goes awry with the signalling. Fat-cell repletion is no longer recognized and rather than there being signals to suppress appetite and increase activity as fat stores increase, there are signals to increase energy intake and reduce energy expenditure ${ }^{(27,29,30,44)}$. In other words, 'eating more' and 'moving less', thought to be causes of body fattening by calorie-focused thinking, may actually be a result of body fattening ${ }^{(27,29,30,44)}$.
So if eating more and moving less could be a result of body fattening, what causes bodies to fatten (i.e. to undergo metabolic dysfunction followed by fat gain, and then weight gain) in the first place; that is, what prevents leptin from doing its job of satiating appetite and promoting energy expenditure? The answer is not entirely clear, but one hypothesis implicates concentrated sources of rapidly absorbable carbohydrates in the diet and the hormone insulin.

Insulin is a pancreatic hormone that helps drive ingested nutrients into cells; its release is most brisk and pronounced following the ingestion of rapidly absorbable carbohydrates (as compared with fats, proteins, alcohol and more slowly absorbed carbohydrates $\left.{ }^{(6,45-48)}\right)$. Rapidly absorbable carbohydrates - sugars and refined starches like white rice and foods consisting substantively of white flour - cause blood sugar to rise briskly and insulin levels to respond in kind ${ }^{(45-48)}$. The rapid insulin elevations produced by these foods cause correspondingly rapid drops in blood sugar. Food cravings result (to restore fallen fuel levels), particularly appetites for something sweet $^{(6,48)}$. Thus, in the short term, intake of rapidly absorbable carbohydrates may promote 'eating more' in general and create a reinforcing loop for overconsumption of additional rapidly absorbable (sweet) carbohydrates in particular (Fig. 1) ${ }^{(27,48)}$.

Over the long term, overconsumption of rapidly absorbable carbohydrates may promote leptin resistance. Such resistance may occur through microbiota-mediated inflammatory pathways ${ }^{(49)}$ or through other metabolic changes (e.g. chronic insulin elevations) ${ }^{(27)}$. Regardless, with leptin's actions largely disabled, the result of high sugar and starch intake is a neurohormonal drive to 'eat more' and 'move less' (Fig. 1) ${ }^{(27,48,49)}$.

By more-nuanced thinking, then, what counts for obesity and related diseases is not the number of calories in specific foods but rather the concentration and type of carbohydrates these foods contain ${ }^{(30,49,50)}$. Total calorie balance is important in both ways of thinking, but whereas calorie-focused thinking directs dietary recommendations towards calorie counts (being primarily quantitative), more-nuanced thinking directs dietary recommendations towards calorie sources (being primarily qualitative); the number of calories consumed and expended are only secondary/intermediate considerations.

\section{Different dietary recommendations by calorie- focused thinking and more-nuanced thinking}

A comparison of selected foods that might be encouraged or discouraged by calorie-focused thinking and a morenuanced thinking appears in Fig. 2. Concordant cells reveal there is some common ground. For example, both ways of thinking discourage sodas, but whereas morenuanced thinking discourages sodas based on 


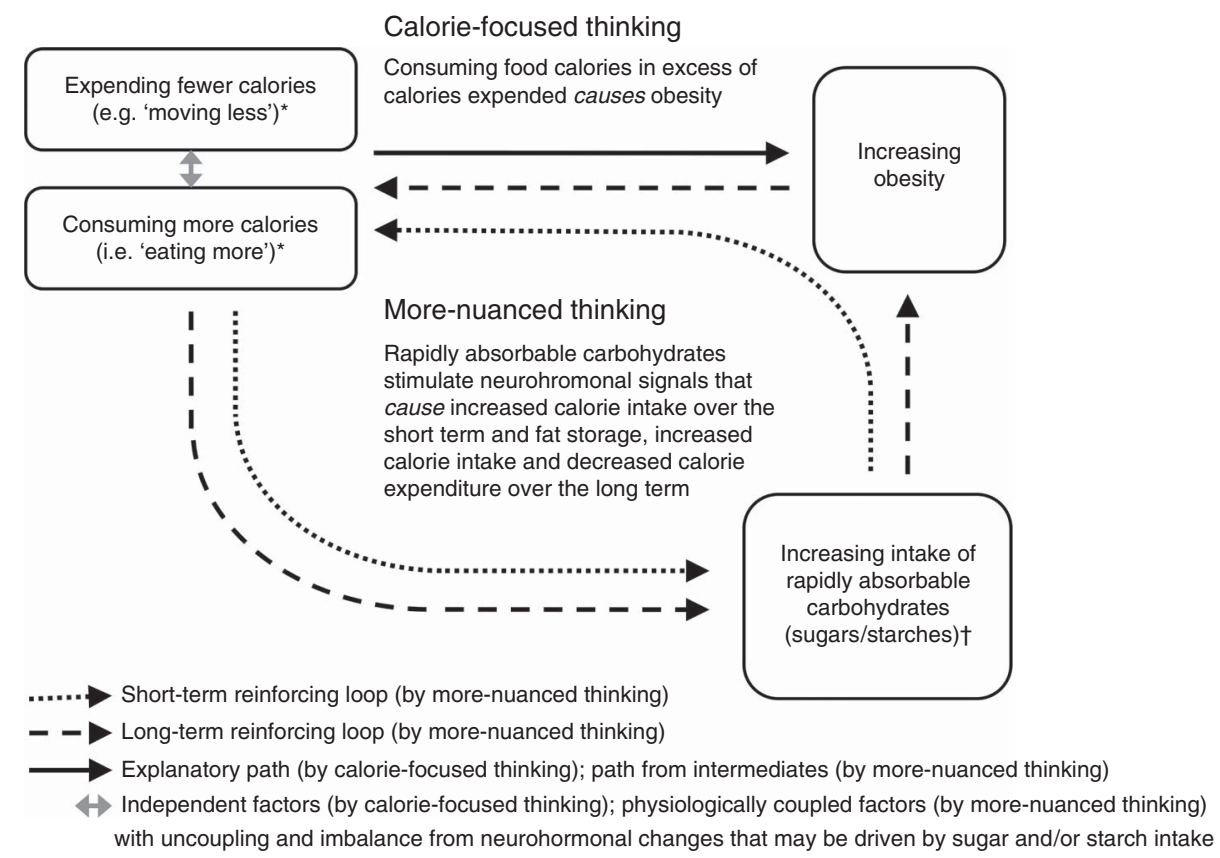

Fig. 1 Calorie-focused thinking versus more-nuanced thinking about obesity. Single-headed arrows represent direct associations in presumed causal directions. *'Expending fewer calories' includes all energy expenditure, but 'moving less' specifically refers to a relatively lower degree of physical inactivity from baseline. 'Eating more' refers to relative overeating from baseline. †Over the short term, the intake of rapidly absorbable carbohydrates - through spikes in blood sugar and insulin, and through sweet cravings promotes a reinforcing loop with 'eating more' in general and eating more rapidly absorbable carbohydrates in particular (dotted arrows). Over the long term, neurohormonal alterations, perhaps chiefly through insulin and leptin resistance - leading to and contributed by growing abdominal fat - perpetuate an indirect reinforcing loop with 'eating more' (dashed arrows) and also promote 'moving less'. Decreasing the intake of rapidly absorbed sugars and starches (as found abundantly in processed foods) and increasing the consumption of whole/minimally processed foods may disrupt these loops, overall calorie imbalance, and both the hormonal dysfunction and excess body mass characterizing obesity

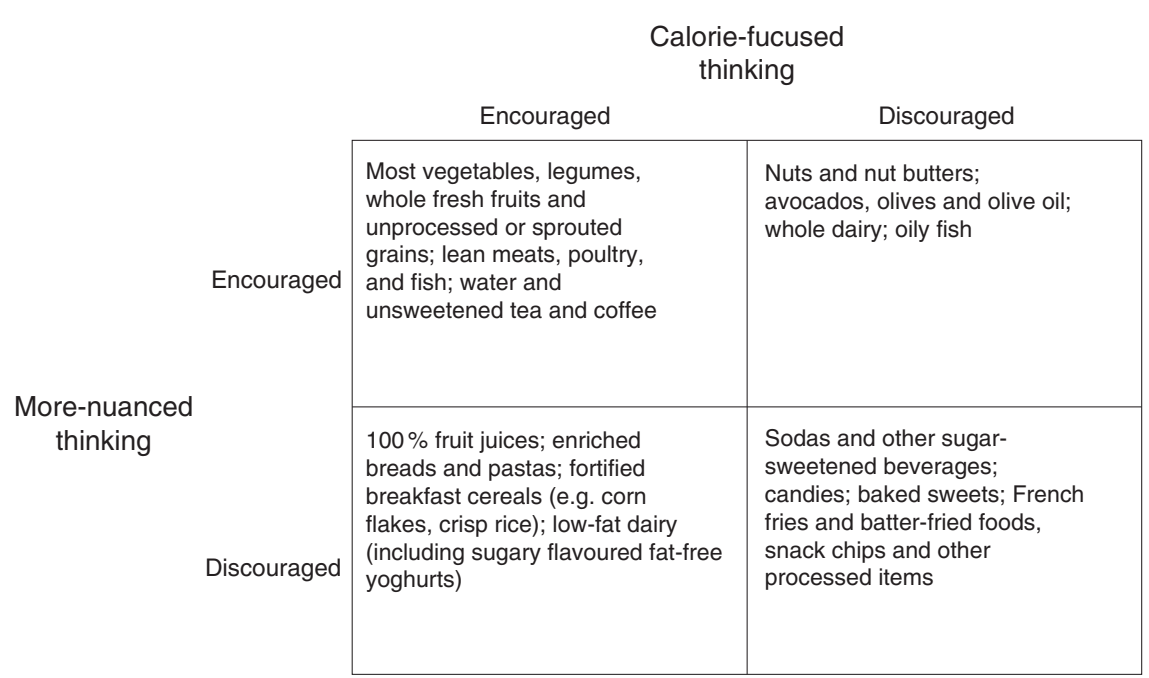

Fig. 2 Comparison of selected foods that might be encouraged or discouraged by calorie-focused thinking and more-nuanced thinking. This figure is not comprehensive, is not a description of any specific diet plan, and does not represent the recommendations or guidelines of any particular individual or organization. It does not explicitly address issues relevant to public health nutrition beyond calorie- and carbohydrate-related concerns (e.g. food production, climate change, One Health, etc.). Additionally, categorizations are based on somewhat relative concepts such as how 'empty' calories are and how 'rapidly absorbable' carbohydrate content is; placement of listed and unlisted items within the construct may be debatable. 'Encouraged' = okay to eat or even desirable as a focus of one's diet, particularly as an alternative to foods that are 'discouraged'; 'discouraged' = to be avoided or limited in quantity 
carbohydrate content and character (i.e. high concentrations of rapidly absorbable sugar), calorie-focused thinking discourages sodas based on the idea of 'empty calories'. 'Empty calories' are foods that contribute energy but few substances thought to be beneficial like vitamins, minerals and fibre. By calorie-focused thinking, 'empty calories' waste precious space on the intake side of calorie balance sheets.

Figure 2 also demonstrates important discordance between calorie-focused thinking and more-nuanced thinking. For instance, $100 \%$ fruit juices - full of vitamins, minerals and sometimes fibre - are not 'empty' and may even be considered healthy and desirable by caloriefocused thinking ${ }^{(51)}$. By more-nuanced thinking, however, $100 \%$ fruit juices are just as undesirable as sodas given both are mostly sugar in concentrated liquid form ${ }^{(52)}$.

Other discordances in dietary recommendations between calorie-focused thinking and more-nuanced thinking, and perhaps the most important differences, relate to dietary fat. Dietary fat has by far the most calories of any of the energy-providing compounds in food: about $9 \mathrm{kcal} / \mathrm{g}$ as compared with roughly $7 \mathrm{kcal} / \mathrm{g}$ for alcohol, $4 \mathrm{kcal} / \mathrm{g}$ for protein and $4 \mathrm{kcal} / \mathrm{g}$ for carbohydrate ${ }^{(53)}$. Thus, calorie-focused thinking has an inherent bias against dietary fat. This bias leads to public health messages and interventions to decrease the intake of fatty foods or reduce or remove the fat from high-fat foods (often replacing fat with less-calorie-dense - often rapidly absorbable - carbohydrates).

Calorie-focused thinking generally endorses foods that are low in fat and calories, as long as those calories are not 'empty'. In contrast, more-nuanced thinking has no problems with fat or calories, per se, and places the blame squarely on foods with the most rapidly absorbable carbohydrates (Fig. 2). Clearly these two ways of thinking are very different. A question for public health moving forward is: would food choices that could result from a continued primary focus on calories (calorie-focused thinking - Fig. 2) be best for population weight and health?

\section{Pertinent clinical and population evidence for two different ways of thinking}

Consider an experiment in children ${ }^{(54)}$. Sixth graders with comparable baseline satiety were allowed to eat as much as they wanted of two highly palatable child-friendly snacks: cheese wedges/rounds or potato chips. A quantity of cheese (mostly fat with some protein and negligible carbohydrate) might offer about $50 \%$ more calories than an identical quantity of chips (mostly carbohydrate and fat with negligible protein). By calorie-focused thinking, comparably hungry children should eat more calories of cheese because cheese has more calories. By morenuanced thinking, comparably hungry children should eat more calories of chips because chips, being rich in rapidly absorbable starch, should tend to promote continued eating (short-term reinforcing loop, Fig. 1) ${ }^{(48)}$.

What actually happened in the experiment was that children in the potato chip group consumed over three times more calories than children in the cheese group ${ }^{(54)}$. While a protein difference between the snacks might certainly have been a factor (with experimental trials suggesting a superior ${ }^{(55)}$, albeit not always statistically significant ${ }^{(56)}$, satiating power of protein), all foods are inevitable mixes of different components and the point here is that the food with the higher starch content prompted greater consumption. This result is consistent with a meta-analysis showing children have greater energy intake following consumption of the most rapidly absorbable carbohydrates ${ }^{(57)}$.

Notably in the experiment described above, the effect of eating more calories in the high-carbohydrate (chips) condition was even more pronounced among overweight and obese children ${ }^{(54)}$. This result is consistent with another trial showing greater hunger in obese children after a high-carbohydrate meal ${ }^{(7)}$ and consistent with the long-term reinforcing loop in Fig. 1.

Although the chips-and-cheese experiment did not assess children's total caloric intake for the day outside of the single snack episode, it is likely that children consuming cheese ate fewer calories overall for the day, whereas children consuming chips ate more. Such an outcome would be suggested by fifteen of sixteen singleday studies in adults that showed increased hunger, lower satiety or greater calorie intake after consuming rapidly absorbable carbohydrates $v$. not ${ }^{(58)}$. The outcome might also be suggested by two other studies in children in which restaurant fast-food consumption was associated with a net increase in total energy intake for the day ${ }^{(59,60)}$ although only for overweight individuals in one study ${ }^{(60)}$, consistent with the long-term reinforcing loop in Fig. 1. Granted, for a given fast-food meal, the studies referenced above cannot distinguish if greater total caloric intake was the result of a greasy burger (per calorie-focused thinking), a refined bun (per more-nuanced thinking) or accompanying French fries (per both ways of thinking). However, substantial evidence now implicates foods that are low in fat (and, thus, relatively low in calories), like potatoes $^{(61)}$, white rice ${ }^{(62)}$ and sugary beverages ${ }^{(61,63-66)}$, in the development and persistence of obesity and risk for related diseases. Conversely, evidence is mounting to exonerate higher-calorie foods that are rich in fat like nuts ${ }^{(61,67-74)}$, oily fish ${ }^{(75)}$ and olive oil ${ }^{(69,76,77)}$, and even foods high in saturated fat ${ }^{(78,79)}$ like dairy products ${ }^{(80-88)}$. Indeed, higher-calorie fattier foods and higher-fat diets may produce and sustain as much or more weight loss than calorie-restricted or higher-carbohydrate diets ${ }^{(9,10,89-98)}$ particularly among those already having metabolic abnormalities ${ }^{(93,94,99)}$. Moreover, certain fattier/lower-carbohydrate diets may also be associated with favourable metabolic indicators ${ }^{(10,89,91-94,98-109)}$, reduced adverse health events ${ }^{(69,102,110,111)}$ and delayed mortality ${ }^{(110-113)}$. 
Table 1 Notions derived from calorie-focused thinking and challenges to those notions

Notion

1. 'A calorie is a calorie'

2. 'Eating less' and 'moving more' to achieve calorie deficit will produce weight loss

3. Consuming more calories than expended causes obesity

4. High-calorie foods/diets (i.e. high-fat foods/diets) are undesirable

5. Low-calorie foods/diets (i.e. low-fat foods/ diets) are desirable

6. Low-fat foods without 'empty calories' are best
Challenge

1. Calories from protein, fat, carbohydrate and alcohol each stimulate different physiological pathways and have different metabolic effects

2. Trying to underconsume calories (without paying attention to qualitative differences in calorie sources) will result in compensatory hunger and fatigue, generally with little weight/fat loss in the short term and rebound weight gain in the long term

3. Energy consumption and expenditure are dependently linked; consuming more calories than needed results in compensatory energy expenditure (e.g. reduced metabolic efficiency) and/or reduced appetite and subsequent intake. If calories are consumed in excess of calories expended in some kind of sustained way, then such imbalance is the result - not the cause - of developing obesity (and of the neurohormonal changes that underlie it)

4. Many foods that are higher in fat may protect against obesity, lead to favourable metabolic indicators and help protect against chronic diseases and early mortality

5. Low-fat foods and diets are often high in the most rapidly absorbable sugars and starches), which may be distinctly detrimental for obesity and related diseases

6. Even for foods that have vitamins, minerals, fibre, and various other constituents believed to be healthy, if they are concentrated sources of rapidly absorbable sugars and starches, they are likely to cause metabolic dysfunction and harm

\section{The situation for public health moving forward}

Fuelled not exclusively but in no small part by caloriefocused thinking, fats in foods and fattier diets became the enemies of public health campaigns of the 1980s and 1990s. Lower-calorie sugars replaced higher-calorie oils in many foods and people shifted their consumption from fats to carbohydrates (most often, the rapidly absorbable kinds). As in the chips-and-cheese experiment described above, greater refined carbohydrate intake was associated with greater total calorie intake, but now on a population level ${ }^{(114,115)}$. In other words, people did not eat less when lower-calorie foods and diets were advised, they ate more. Obesity rates increased right along with greater consumption $^{(114,115)}$. Diabetes rates increased too ${ }^{(116,117)}$ and although these findings do not prove causation, they certainly do not support continuing forward under the current logic of calorie-focused thinking, with the food choices it could encourage (Fig. 2) or the tenuous notions that follow from it (Table 1).

Calorie-focused public health initiatives might continue to produce unintended, even ironic, consequences. Initiatives like calorie labelling for example - first for food packages and more recently for restaurant menus and menu boards are meant to steer both consumer choices and food-industry offerings towards lower-calorie options ${ }^{(118)}$. Despite national enthusiasm for the idea ${ }^{(119,120)}$, whether calorie labelling will have the desired effect seems doubtful ${ }^{(121-124)}$. Also in doubt is whether labelling will actually improve population health. There is already suggestion that some labelling may produce effects opposite to those intended ${ }^{(125)}$. And there is the distinct possibility that calorie labelling could further move food production and consumption away from healthful high-fat foods (like nuts) and towards sugary and starchy items (like low-fat baked potato chips), promoting further increases in diseases characterized by abdominal fat and metabolic dysfunction.
There are, admittedly, other existing public health initiatives that, at least on the surface, seem more consistent with the logic of 'more-nuanced thinking'; for instance, proposals to tax and limit sugary beverages ${ }^{(52,126,127)}$. Nevertheless, these initiatives are usually framed around the idea of 'empty calories', which totally misses the point. Even the Food and Drug Administration's proposed changes to packaged-food labels - which would newly report the amount of 'added sugars' in a product - place even more emphasis on calories than current labels by visually subordinating all other label information and highlighting calories in an enormous bold typeface ${ }^{(128)}$.

What existing and planned initiatives seem not to acknowledge is that calories from added sugars and starches are worse than just 'empty' (detriment through omission); evidence suggests they are actively harmful (detriment through commission) ${ }^{(61,62,129,130)}$. While responses of individual consumers may vary (e.g. due to their personal genetic susceptibility $^{(48,63)}$ or that of their resident gut microbes $\left.{ }^{(131)}\right)$, there is good reason to believe that rapidly absorbable carbohydrates tend to promote obesity, and diseases commonly associated with it, in general $^{(45,48,63,132-137)}$.

The problem for public health is that continuing to focus on quantifying calories may misdirect thinking on obesity and related diseases and promote destructive messages. For instance, in a 2013 editorial, the president of the Institute of Medicine listed gluttony and sloth as 'obvious' 'deadly sins' for public health to address ${ }^{(138)}$. His argument (which had been made before ${ }^{(139)}$ ) suggested obesity and related diseases are matters only of personal resolve and self-control; if people just had more motivation and will-power, they could consciously control their calorie balance sheets, eat less, move more and lose weight. It stands to reason that those subscribing to the Institute of Medicine logic might blame an overconsuming, inactive adolescent for growing fat. But would they blame the same overconsuming, inactive adolescent for growing tall? 
Just as children do not enter puberty and grow tall because they overeat and sleep more, neither do individuals start to fatten and become obese because they eat too much and move too little. In both cases overconsumption and inactivity are intermediate effects; neurohormonal changes are the cause. The case of pubertal growth represents normal development, but the case of fattening represents decided pathology; pathology that may be modifiable through dietary change. Perhaps if we shifted food production and people's consumption away from added sugars and refined starches, we could avoid the resultant metabolic dysfunction and corpulence that have come to plague our populations. Instead of futilely promoting messages to 'eat less' and 'move more,(13,139), perhaps we should do more to promote the consumption of whole/minimally processed foods ${ }^{(140)}$ - like more of those in the upper row of Fig. 2 - foods that might make 'eating less' and moving more' more possible.

\section{Concluding thoughts}

Calorie-focused thinking may have already exacerbated the epidemics of obesity and related diseases. And while there has been much progress in redirecting dietary focus towards actual foods ${ }^{(141)}$, there is still too much focus on eating 'too much',(15). Focusing quantitatively, particularly on the calories available from specific foods, fails to recognize the broader metabolic effects of foods themselves. Foods that are highly processed and comprised mostly of rapidly absorbable sugars and starches may be of greatest concern. Such carbohydrates may induce neurohormonal changes that might, in turn, help produce the overeating and inactivity often interpreted as causative for obesity. In other words, unhealthy foods may make double victims of their consumers, who might not only become obese by eating them but also receive harsh criticism for their substantial appetites and apparent laziness that result.

As the saying often attributed to the Albert Einstein goes, 'not everything that can be counted counts', and advice to count calories, or to try to change calorie balance sheets by intervening on quantities of undifferentiated foods, seems misdirected. Imagine comparably misdirected advice: for instance, to count fluid ounces, drink less and urinate more - advice that might likewise result in temporary weight loss (but no fat loss) and be uncomfortable, unsustainable, unreasonable and unhelpful; and likewise oppose coupled neurohormonally driven physiology in futility. Yes, calories count, and calorie balance sheets matter, but net intake or expenditure probably results more from qualitative distinctions in the foods we eat than conscious attempts at quantitative control $^{(30)}$. New public health initiatives and messages focused on encouraging consumption of whole/minimally processed foods would be ideal ${ }^{(140)}$, especially to counteract industry's near-exclusive marketing of foods that are highly processed/refined and concentrated sources of the most rapidly absorbable starches and sugars.

Promoting the consumption of whole foods will require careful attention to food systems, cultural traditions, peer influences, food environments, assistance programmes and a host of other issues beyond the scope of the present commentary. But as a guiding principle, the public health community should not be trying to cut calories from available foods ${ }^{(142)}$, we should be improving the quality of the foods available that provide our calories. We should be promoting foods that do not prompt, or indeed programme, us to overeat.

Although focusing on refined starch and sugar content might seem like a logical path forward, such narrow focus could lead to unintended consequences, as when public health campaigns demonized fat. For this reason, the recent WHO draft guideline to more strictly limit the intake of all sugars ${ }^{(143)}$, the recent proposition in England for a sugar $\operatorname{tax}^{(144)}$, and the recent proposal in California to place health warning labels on sugary drinks ${ }^{(145)}$, while all appropriately focused, should be evaluated carefully before wider implementation. Coordination with the food industry will be challenging, but while working towards improving the quality of foods that are produced and working to support the consumption of whole/minimally processed products, at the very least, public health should not continue to promote messages that create and blame victims or that, in all likelihood, continue to exacerbate epidemics of obesity and related diseases.

\section{Acknowledgements}

Acknowledgements: S.C.L. would like to thank Sanjay Basu, MD, PhD, Jennifer L Pomeranz, JD, MPH, Paul R Marantz, MD, MPH and Manisha Sharma, MD for reviewing very early drafts of this manuscript and providing critical comments. Financial support: This research received no specific grant from any funding agency in the public, commercial or not-for-profit sectors. Conflict of interest: None. Authorship: S.C.L. conducted the primary literature review, conceived the paper, drafted the main arguments, and created Figs 1 and 2. J.J.D. helped revise the text, contributed citations, and drafted Table 1.

\section{References}

1. Huffman DM \& Barzilai N (2010) Contribution of adipose tissue to health span and longevity. Interdiscip Top Gerontol 37, 1-19.

2. Neeland IJ, Ayers CR, Rohatgi AK et al. (2013) Associations of visceral and abdominal subcutaneous adipose tissue with markers of cardiac and metabolic risk in obese adults. Obesity (Silver Spring) 21, E439-E447.

3. Oliveros E, Somers VK, Sochor O et al. (2014) The concept of normal weight obesity. Prog Cardiovasc Dis 56, 426-433. 
4. Thomas JE (1957) Mechanics and regulation of gastric emptying. Physiol Rev 37, 453-474.

5. Benedini S, Codella R, Caumo A et al. (2011) Different circulating ghrelin responses to isoglucidic snack food in healthy individuals. Horm Metab Res 43, 135-140.

6. Raben A, Agerholm-Larsen L, Flint A et al. (2003) Meals with similar energy densities but rich in protein, fat, carbohydrate, or alcohol have different effects on energy expenditure and substrate metabolism but not on appetite and energy intake. Am J Clin Nutr 77, 91-100.

7. Lomenick JP, Melguizo MS, Mitchell SL et al. (2009) Effects of meals high in carbohydrate, protein, and fat on ghrelin and peptide YY secretion in prepubertal children. J Clin Endocrinol Metab 94, 4463-4471.

8. Riera-Crichton D \& Tefft N (2014) Macronutrients and obesity: revisiting the calories in, calories out framework. Econ Hum Biol 14, 33-49.

9. Kekwick A \& Pawan GL (1956) Calorie intake in relation to body-weight changes in the obese. Lancet 271, 155-161.

10. Ebbeling CB, Swain JF, Feldman HA et al. (2012) Effects of dietary composition on energy expenditure during weightloss maintenance. JAMA 307, 2627-2634.

11. Gerstein DE, Woodward-Lopez G, Evans AE et al. (2004) Clarifying concepts about macronutrients' effects on satiation and satiety. J Am Diet Assoc 104, 1151-1153.

12. Feinman RD \& Fine EJ (2004) 'A calorie is a calorie' violates the second law of thermodynamics. Nutr J 3, 9 .

13. Shook RP, Hand GA \& Blair SN (2014) Top 10 research questions related to energy balance. Res Q Exerc Sport $\mathbf{8 5}$, 49-58.

14. Westerterp KR, Wilson SA \& Rolland V (1999) Diet induced thermogenesis measured over $24 \mathrm{~h}$ in a respiration chamber: effect of diet composition. Int J Obes Relat Metab Disord 23, 287-292.

15. Guth E (2014) JAMA patient page. Healthy weight loss. JAMA 312, 974.

16. Baer DJ, Gebauer SK \& Novotny JA (2012) Measured energy value of pistachios in the human diet. BrJ Nutr 107, 120-125.

17. Urban LE, Dallal GE, Robinson LM et al. (2010) The accuracy of stated energy contents of reduced-energy, commercially prepared foods. J Am Diet Assoc 110, 116-123.

18. Hall KD, Heymsfield SB, Kemnitz JW et al. (2012) Energy balance and its components: implications for body weight regulation. Am J Clin Nutr 95, 989-994.

19. Novotny JA, Gebauer SK \& Baer DJ (2012) Discrepancy between the Atwater factor predicted and empirically measured energy values of almonds in human diets. $A m J$ Clin Nutr 96, 296-301.

20. Lee JM, Kim Y \& Welk GJ (2014) Validity of consumerbased physical activity monitors. Med Sci Sports Exerc 46, 1840-1848.

21. Jakubowicz D, Barnea M, Wainstein J et al. (2013) High caloric intake at breakfast vs. dinner differentially influences weight loss of overweight and obese women. Obesity (Silver Spring) 21, 2504-2512.

22. Leibel RL, Rosenbaum M \& Hirsch J (1995) Changes in energy expenditure resulting from altered body weight. $N$ Engl J Med 332, 621-628.

23. Harris RB (1990) Role of set-point theory in regulation of body weight. FASEB J 4, 3310-3318.

24. St Clair Gibson A, Goedecke JH, Harley YX et al. (2005) Metabolic setpoint control mechanisms in different physiological systems at rest and during exercise. J Theor Biol 236, 60-72.

25. Sumithran P \& Proietto J (2013) The defence of body weight: a physiological basis for weight regain after weight loss. Clin Sci (Lond) 124, 231-241.

26. Ochner CN, Barrios DM, Lee CD et al. (2013) Biological mechanisms that promote weight regain following weight loss in obese humans. Physiol Behav 120, 106-113.
27. Lustig RH (2006) The 'skinny' on childhood obesity: how our western environment starves kids' brains. Pediatr Ann 35, 898-902.

28. Heymsfield SB, Harp JB, Reitman ML et al. (2007) Why do obese patients not lose more weight when treated with low-calorie diets? A mechanistic perspective. Am J Clin Nutr 85, 346-354.

29. Speakman JR, Levitsky DA, Allison DB et al. (2011) Set points, settling points and some alternative models: theoretical options to understand how genes and environments combine to regulate body adiposity. Dis Model Mech 4, 733-745.

30. Ludwig DS \& Friedman MI (2014) Increasing adiposity: consequence or cause of overeating? JAMA 311, 2167-2168

31. Hall KD, Hammond RA \& Rahmandad H (2014) Dynamic interplay among homeostatic, hedonic, and cognitive feedback circuits regulating body weight. Am J Public Health 104, 1169-1175.

32. Nackers LM, Middleton KR, Dubyak PJ et al. (2013) Effects of prescribing 1,000 versus 1,500 kilocalories per day in the behavioral treatment of obesity: a randomized trial. Obesity (Silver Spring) 21, 2481-2487.

33. Maclean PS, Bergouignan A, Cornier MA et al. (2011) Biology's response to dieting: the impetus for weight regain. $A m$ J Physiol Regul Integr Comp Physiol 301, R581-R600.

34. Hall KD, Sacks G, Chandramohan D et al. (2011) Quantification of the effect of energy imbalance on bodyweight. Lancet 378, 826-837.

35. Hall KD, Butte NF, Swinburn BA et al. (2013) Dynamics of childhood growth and obesity: development and validation of a quantitative mathematical model. Lancet Diabetes Endocrinol 1, 97-105.

36. Shah NR \& Braverman ER (2012) Measuring adiposity in patients: the utility of body mass index (BMI), percent body fat, and leptin. PLoS One 7, e33308.

37. Wildman RP, Muntner P, Reynolds K et al. (2008) The obese without cardiometabolic risk factor clustering and the normal weight with cardiometabolic risk factor clustering: prevalence and correlates of 2 phenotypes among the US population (NHANES 1999-2004). Arch Intern Med 168, 1617-1624.

38. Coutinho T, Goel K, Correa de Sa D et al. (2013) Combining body mass index with measures of central obesity in the assessment of mortality in subjects with coronary disease: role of 'normal weight central obesity'. J Am Coll Cardiol 61, 553-560.

39. Song Y, Manson JE, Meigs JB et al. (2007) Comparison of usefulness of body mass index versus metabolic risk factors in predicting 10-year risk of cardiovascular events in women. Am J Cardiol 100, 1654-1658.

40. Hamer M \& Stamatakis E (2012) Metabolically healthy obesity and risk of all-cause and cardiovascular disease mortality. J Clin Endocrinol Metab 97, 2482-2488.

41. Kramer CK, Zinman B \& Retnakaran R (2013) Are metabolically healthy overweight and obesity benign conditions? A systematic review and meta-analysis. Ann Intern Med 159, 758-769.

42. Gannon MC \& Nuttall FQ (2006) Control of blood glucose in type 2 diabetes without weight loss by modification of diet composition. Nutr Metab (Lond) 3, 16.

43. Look AHEAD Research Group, Wing RR \& Bolin P (2013) Cardiovascular effects of intensive lifestyle intervention in type 2 diabetes. $N$ Engl J Med 369, 145-154.

44. Richmond RC, Davey Smith G, Ness AR et al. (2014) Assessing causality in the association between child adiposity and physical activity levels: a Mendelian randomization analysis. PLoS Med 11, e1001618.

45. Mann J (2007) Dietary carbohydrate: relationship to cardiovascular disease and disorders of carbohydrate metabolism. Eur J Clin Nutr 61, Suppl. 1, S100-S111. 
46. Jenkins DJ, Wolever TM, Taylor RH et al. (1981) Glycemic index of foods: a physiological basis for carbohydrate exchange. Am J Clin Nutr 34, 362-366.

47. Foster-Powell K, Holt SH \& Brand-Miller JC (2002) International table of glycemic index and glycemic load values. Am J Clin Nutr 76, 5-56.

48. Ludwig DS (2002) The glycemic index: physiological mechanisms relating to obesity, diabetes, and cardiovascular disease. JAMA 287, 2414-2423.

49. Spreadbury I (2012) Comparison with ancestral diets suggests dense acellular carbohydrates promote an inflammatory microbiota, and may be the primary dietary cause of leptin resistance and obesity. Diabetes Metab Syndr Obes 5, 175-189.

50. Taubes G (2012) Treat obesity as physiology, not physics. Nature 492, 155.

51. Nicklas T, Kleinman RE \& O'Neil CE (2012) Taking into account scientific evidence showing the benefits of $100 \%$ fruit juice. Am J Public Health 102, e4.

52. Wojcicki JM \& Heyman MB (2012) Reducing childhood obesity by eliminating 100\% fruit juice. Am J Public Health 102, 1630-1633.

53. Atwater WO (1899) Experiments on the Metabolism of Matter and Energy in the Human Body. Washington, DC: Government Printing Office.

54. Wansink B, Shimizu M \& Brumberg A (2013) Association of nutrient-dense snack combinations with calories and vegetable intake. Pediatrics 131, 22-29.

55. Marmonier C, Chapelot D \& Louis-Sylvestre J (2000) Effects of macronutrient content and energy density of snacks consumed in a satiety state on the onset of the next meal. Appetite 34, 161-168.

56. Vozzo R, Wittert G, Cocchiaro C et al. (2003) Similar effects of foods high in protein, carbohydrate and fat on subsequent spontaneous food intake in healthy individuals. Appetite 40, 101-107.

57. Rouhani MH, Salehi-Abargouei A \& Azadbakht L (2013) Effect of glycemic index and glycemic load on energy intake in children. Nutrition 29, 1100-1105.

58. Ludwig DS (2000) Dietary glycemic index and obesity. J Nutr 130, 2 S Suppl., 280S-283S.

59. Powell LM \& Nguyen BT (2013) Fast-food and full-service restaurant consumption among children and adolescents: effect on energy, beverage, and nutrient intake. $A r c h$ Pediatr Adolesc Med 167, 14-20.

60. Ebbeling CB, Sinclair KB, Pereira MA et al. (2004) Compensation for energy intake from fast food among overweight and lean adolescents. JAMA 291, 2828-2833.

61. Mozaffarian D, Hao T, Rimm EB et al. (2011) Changes in diet and lifestyle and long-term weight gain in women and men. N Engl J Med 364, 2392-2404.

62. Hu EA, Pan A, Malik V et al. (2012) White rice consumption and risk of type 2 diabetes: meta-analysis and systematic review. BMJ 344, e1454.

63. Qi Q, Chu AY, Kang JH et al. (2012) Sugar-sweetened beverages and genetic risk of obesity. $N$ Engl J Med 367, 1387-1396.

64. Faith MS, Dennison BA, Edmunds LS et al. (2006) Fruit juice intake predicts increased adiposity gain in children from low-income families: weight status-by-environment interaction. Pediatrics 118, 2066-2075.

65. Malik VS, Schulze MB \& Hu FB (2006) Intake of sugarsweetened beverages and weight gain: a systematic review. Am J Clin Nutr 84, 274-288.

66. Bes-Rastrollo M, Schulze MB, Ruiz-Canela M et al. (2013) Financial conflicts of interest and reporting bias regarding the association between sugar-sweetened beverages and weight gain: a systematic review of systematic reviews. PLoS Med 10, e1001578.
67. Tan SY \& Mattes RD (2013) Appetitive, dietary and health effects of almonds consumed with meals or as snacks: a randomized, controlled trial. Eur J Clin Nutr $\mathbf{6 7}$, 1205-1214

68. Tey SL, Brown R, Gray A et al. (2011) Nuts improve diet quality compared to other energy-dense snacks while maintaining body weight. J Nutr Metab 2011, 357350.

69. Estruch R, Ros E, Salas-Salvado J et al. (2013) Primary prevention of cardiovascular disease with a Mediterranean diet. N Engl J Med 368, 1279-1290.

70. Guasch-Ferre M, Bullo M, Martinez-Gonzalez MA et al. (2013) Frequency of nut consumption and mortality risk in the PREDIMED nutrition intervention trial. BMC Med 11, 164.

71. Bao Y, Han J, Hu FB et al. (2013) Association of nut consumption with total and cause-specific mortality. N Engl J Med 369, 2001-2011.

72. Ma Y, Njike VY, Millet J et al. (2010) Effects of walnut consumption on endothelial function in type 2 diabetic subjects: a randomized controlled crossover trial. Diabetes Care 33, 227-232.

73. Tan SY, Dhillon J \& Mattes RD (2014) A review of the effects of nuts on appetite, food intake, metabolism, and body weight. Am J Clin Nutr 100, Suppl. 1, 412S-422S.

74. Viguiliouk E, Kendall CW, Blanco Mejia S et al. (2014) Effect of tree nuts on glycemic control in diabetes: a systematic review and meta-analysis of randomized controlled dietary trials. PLoS One 9, e103376.

75. Thorsdottir I, Tomasson H, Gunnarsdottir I et al. (2007) Randomized trial of weight-loss-diets for young adults varying in fish and fish oil content. Int J Obes (Lond) $\mathbf{3 1}$, 1560-1566.

76. Perez-Martinez P, Garcia-Rios A, Delgado-Lista J et al. (2011) Mediterranean diet rich in olive oil and obesity, metabolic syndrome and diabetes mellitus. Curr Pharm Des 17, 769-777.

77. Salas-Salvado J, Bullo M, Estruch R et al. (2014) Prevention of diabetes with Mediterranean diets: a subgroup analysis of a randomized trial. Ann Intern Med 160, 1-10.

78. Siri-Tarino PW, Sun Q, Hu FB et al. (2010) Meta-analysis of prospective cohort studies evaluating the association of saturated fat with cardiovascular disease. Am J Clin Nutr 91, 535-546.

79. Chowdhury R, Warnakula S, Kunutsor S et al. (2014) Association of dietary, circulating, and supplement fatty acids with coronary risk: a systematic review and metaanalysis. Ann Intern Med 160, 398-406.

80. Scharf RJ, Demmer RT \& Deboer MD (2013) Longitudinal evaluation of milk type consumed and weight status in preschoolers. Arch Dis Child 98, 335-340.

81. Rice BH, Quann EE \& Miller GD (2013) Meeting and exceeding dairy recommendations: effects of dairy consumption on nutrient intakes and risk of chronic disease. Nutr Rev 71, 209-223.

82. O'Sullivan TA, Hafekost K, Mitrou F et al. (2013) Food sources of saturated fat and the association with mortality: a meta-analysis. Am J Public Health 103, e31-e42.

83. de Oliveira Otto MC, Mozaffarian D, Kromhout D et al. (2012) Dietary intake of saturated fat by food source and incident cardiovascular disease: the Multi-Ethnic Study of Atherosclerosis. Am J Clin Nutr 96, 397-404.

84. Aune D, Norat T, Romundstad P et al. (2013) Dairy products and the risk of type 2 diabetes: a systematic review and dose-response meta-analysis of cohort studies. Am J Clin Nutr 98, 1066-1083.

85. Holmberg S \& Thelin A (2013) High dairy fat intake related to less central obesity: a male cohort study with 12 years' follow-up. Scand J Prim Health Care 31, 89-94.

86. Kratz M, Baars T \& Guyenet S (2013) The relationship between high-fat dairy consumption and obesity, cardiovascular, and metabolic disease. Eur J Nutr 52, 1-24. 
87. Li S, Field A, Rimm E et al. (2014) Dairy consumption with onset of overweight and obesity among US adolescents. FASEB J 28, 1 Suppl., abstr. 370.7.

88. Martinez-Gonzalez MA, Sayon-Orea C, Ruiz-Canela M et al. (2014) Yogurt consumption, weight change and risk of overweight/obesity: the SUN cohort study. Nutr Metab Cardiovasc Dis (Epublication ahead of print version).

89. Hession M, Rolland C, Kulkarni U et al. (2009) Systematic review of randomized controlled trials of low-carbohydrate vs. low-fat/low-calorie diets in the management of obesity and its comorbidities. Obes Rev 10, 36-50.

90. Spieth LE, Harnish JD, Lenders CM et al. (2000) A lowglycemic index diet in the treatment of pediatric obesity. Arch Pediatr Adolesc Med 154, 947-951.

91. Hu T, Mills KT, Yao L et al. (2012) Effects of lowcarbohydrate diets versus low-fat diets on metabolic risk factors: a meta-analysis of randomized controlled clinical trials. Am J Epidemiol 176, Suppl. 7, S44-S54.

92. Yancy WS Jr, Olsen MK, Guyton JR et al. (2004) A lowcarbohydrate, ketogenic diet versus a low-fat diet to treat obesity and hyperlipidemia: a randomized, controlled trial. Ann Intern Med 140, 769-777.

93. Volek JS, Phinney SD, Forsythe CE et al. (2009) Carbohydrate restriction has a more favorable impact on the metabolic syndrome than a low fat diet. Lipids 44, 297-309.

94. Westman EC, Yancy WS Jr, Mavropoulos JC et al. (2008) The effect of a low-carbohydrate, ketogenic diet versus a low-glycemic index diet on glycemic control in type 2 diabetes mellitus. Nutr Metab (Lond) 5, 36.

95. Tobias DK, Chen M, Willett W et al. (2014) Randomized trials of low-fat vs. other diet interventions on weight loss: a meta-analysis. Circulation 129, Suppl. 1, abstr. MP63.

96. Dutton GR, Laitner MH \& Perri MG (2014) Lifestyle interventions for cardiovascular disease risk reduction: a systematic review of the effects of diet composition, food provision, and treatment modality on weight loss. Curr Atheroscler Rep 16, 442.

97. Johnston BC, Kanters S, Bandayrel K et al. (2014) Comparison of weight loss among named diet programs in overweight and obese adults: a meta-analysis. JAMA $\mathbf{3 1 2}$, 923-933.

98. Gow ML, Ho M, Burrows TL et al. (2014) Impact of dietary macronutrient distribution on BMI and cardiometabolic outcomes in overweight and obese children and adolescents: a systematic review. Nutr Rev 72, 453-470.

99. Ebbeling CB, Leidig MM, Feldman HA et al. (2007) Effects of a low-glycemic load vs low-fat diet in obese young adults: a randomized trial. JAMA 297, 2092-2102.

100. Mensink RP \& Katan MB (1992) Effect of dietary fatty acids on serum lipids and lipoproteins. A meta-analysis of 27 trials. Arterioscler Thromb 12, 911-919.

101. Richard C, Couture P, Desroches S et al. (2013) Effect of the Mediterranean diet with and without weight loss on markers of inflammation in men with metabolic syndrome. Obesity (Silver Spring) 21, 51-57.

102. Corella D, Carrasco P, Sorli JV et al. (2013) Mediterranean diet reduces the adverse effect of the TCF7L2-rs7903146 polymorphism on cardiovascular risk factors and stroke incidence: a randomized controlled trial in a high-cardiovascular-risk population. Diabetes Care 36, 3803-3811.

103. Foster GD, Wyatt HR, Hill JO et al. (2010) Weight and metabolic outcomes after 2 years on a low-carbohydrate versus low-fat diet: a randomized trial. Ann Intern Med 153, $147-157$.

104. Shai I, Spence JD, Schwarzfuchs D et al. (2010) Dietary intervention to reverse carotid atherosclerosis. Circulation 121, 1200-1208.

105. Mobbs CV, Mastaitis J, Isoda F et al. (2013) Treatment of diabetes and diabetic complications with a ketogenic diet. J Child Neurol 28, 1009-1014.
106. Schwingshackl L \& Hoffmann G (2013) Comparison of effects of long-term low-fat vs high-fat diets on blood lipid levels in overweight or obese patients: a systematic review and meta-analysis. J Acad Nutr Diet 113, 1640-1661.

107. Meckling KA, O'Sullivan C \& Saari D (2004) Comparison of a low-fat diet to a low-carbohydrate diet on weight loss, body composition, and risk factors for diabetes and cardiovascular disease in free-living, overweight men and women. J Clin Endocrinol Metab 89, 2717-2723.

108. Gogebakan O, Kohl A, Osterhoff MA et al. (2011) Effects of weight loss and long-term weight maintenance with diets varying in protein and glycemic index on cardiovascular risk factors: the diet, obesity, and genes (DiOGenes) study: a randomized, controlled trial. Circulation 124, 2829-2838.

109. Bazzano LA, Hu T, Reynolds K et al. (2014) Effects of lowcarbohydrate and low-fat diets: a randomized trial. Ann Intern Med 161, 309-318.

110. Fung TT, Rexrode KM, Mantzoros CS et al. (2009) Mediterranean diet and incidence of and mortality from coronary heart disease and stroke in women. Circulation 119, 1093-1100.

111. Sofi F, Macchi C, Abbate R et al. (2014) Mediterranean diet and health status: an updated meta-analysis and a proposal for a literature-based adherence score. Public Health Nutr 17, 2769-2782.

112. Knoops KT, de Groot LC, Kromhout D et al. (2004) Mediterranean diet, lifestyle factors, and 10-year mortality in elderly European men and women: the HALE project. JAMA 292, 1433-1439.

113. Trichopoulou A, Orfanos P, Norat T et al. (2005) Modified Mediterranean diet and survival: EPIC-elderly prospective cohort study. BMJ 330, 991.

114. Marantz PR, Bird ED \& Alderman MH (2008) A call for higher standards of evidence for dietary guidelines. $\mathrm{Am} \mathrm{J}$ Prev Med 34, 234-240.

115. National Center for Health Statistics, Centers for Disease Control and Prevention (2005) Health, United States, 2005 with Chartbook on Trends in the Health of Americans. http://www.cdc.gov/nchs/data/hus/hus05.pdf (accessed April 2013).

116. Centers for Disease Control and Prevention (2012) Increasing prevalence of diagnosed diabetes - United States and Puerto Rico, 1995-2010. MMWR Morb Mortal Wkly Rep 61, 918-921.

117. Centers for Disease Control and Prevention (2013) Number (in Millions) of Civilian, Noninstitutionalized Persons with Diagnosed Diabetes, United States, 1980-2011. http:// www.cdc.gov/diabetes/statistics/prev/national/figpersons. htm (accessed June 2013).

118. Hodge JG Jr \& White LC (2012) Supplementing national menu labeling. Am J Public Health 102, e11-e13.

119. US Food and Drug Administration (2011) FDA Issues Two Proposed Rules on Food Labeling: Nutrition Labeling of Standard Menu Items in Restaurants and Similar Retail Food Establishments; and Calorie Labeling of Articles of Food in Vending Machines. http://www.fda.gov/Food/ NewsEvents/ConstituentUpdates/ucm249206.htm (accessed April 2013).

120. Block JP \& Roberto CA (2014) Potential benefits of calorie labeling in restaurants. JAMA 312, 887-888.

121. Swartz JJ, Braxton D \& Viera AJ (2011) Calorie menu labeling on quick-service restaurant menus: an updated systematic review of the literature. Int J Behav Nutr Phys Act 8, 135 .

122. Elbel B, Mijanovich T, Dixon LB et al. (2013) Calorie labeling, fast food purchasing and restaurant visits. Obesity (Silver Spring) 21, 2172-2179.

123. Kiszko KM, Martinez OD, Abrams C et al. (2014) The influence of calorie labeling on food orders and 
consumption: a review of the literature. J Community Health (Epublication ahead of print version).

124. Sinclair SE, Cooper M \& Mansfield ED (2014) The influence of menu labeling on calories selected or consumed: a systematic review and meta-Analysis. J Acad Nutr Diet 114, 1375-1388.

125. Downs JS, Wisdom J, Wansink B et al. (2013) Supplementing menu labeling with calorie recommendations to test for facilitation effects. Am J Public Health 103, 1604-1609.

126. Brownell KD \& Frieden TR (2009) Ounces of prevention the public policy case for taxes on sugared beverages. $N$ Engl J Med 360, 1805-1808.

127. Brownell KD, Farley T, Willett WC et al. (2009) The public health and economic benefits of taxing sugar-sweetened beverages. $N$ Engl J Med 361, 1599-1605.

128. Wilson J \& Christensen J for CNN (2014) Nutrition labels getting a makeover. http://www.cnn.com/2014/02/27/ health/nutrition-labels-changes/ (accessed February 2014).

129. Schwingshackl L \& Hoffmann G (2013) Long-term effects of low glycemic index/load vs. high glycemic index/load diets on parameters of obesity and obesity-associated risks: a systematic review and meta-analysis. Nutr Metab Cardiovasc Dis 23, 699-706.

130. Te Morenga LA, Howatson AJ, Jones RM et al. (2014) Dietary sugars and cardiometabolic risk: systematic review and meta-analyses of randomized controlled trials of the effects on blood pressure and lipids. Am J Clin Nutr 100, 65-79.

131. Turnbaugh PJ, Ridaura VK, Faith JJ et al. (2009) The effect of diet on the human gut microbiome: a metagenomic analysis in humanized gnotobiotic mice. Sci Transl Med 1, Gra14.

132. Sorensen LB, Raben A, Stender S et al. (2005) Effect of sucrose on inflammatory markers in overweight humans. Am J Clin Nutr 82, 421-427.

133. Te Morenga L, Mallard S \& Mann J (2012) Dietary sugars and body weight: systematic review and meta-analyses of randomised controlled trials and cohort studies. BMJ 346, e7492.

134. Basu S, Yoffe P, Hills N et al. (2013) The relationship of sugar to population-level diabetes prevalence: an econometric analysis of repeated cross-sectional data. PLOS One 8, e57873.

135. Tavani A, Giordano L, Gallus S et al. (2006) Consumption of sweet foods and breast cancer risk in Italy. Ann Oncol 17, 341-345.

136. Schernhammer ES, Hu FB, Giovannucci E et al. (2005) Sugar-sweetened soft drink consumption and risk of pancreatic cancer in two prospective cohorts. Cancer Epidemiol Biomarkers Prev 14, 2098-2105.

137. Yang Q, Zhang Z, Gregg EW et al. (2014) Added sugar intake and cardiovascular diseases mortality among US adults. JAMA Intern Med 174, 516-524.

138. Fineberg HV (2013) Public health in a time of government austerity. Am J Public Health 103, 47-49.

139. Ramos Salas X, Forhan M \& Sharma AM (2014) Diffusing obesity myths. Clin Obes 4, 189-196.

140. Mozaffarian D, Rogoff KS \& Ludwig DS (2014) The real cost of food: can taxes and subsidies improve public health? JAMA 312, 889-890.

141. Katz DL \& Meller S (2014) Can we say what diet is best for health? Annu Rev Public Health 35, 83-103.

142. Robert Wood Johnson Foundation (2014) Major Food, Beverage Companies Remove 6.4 Trillion Calories from US Marketplace. http://www.rwjf.org/en/about-rwjf/newsroom/ newsroom-content/2014/01/major-food-beverage-companiesremove-6-4-trillion-calories-fro.html?cid=xrs_rss-pr (accessed March 2014).

143. World Helath Organization (2014) WHO opens public consultation on draft sugars guideline. http://who.int/ mediacentre/news/notes/2014/consultation-sugar-guideline/ en/ (accessed March 2014).

144. BBC News (2014) Sugar tax may be necessary, England's chief medical officer says. http://www.bbc.com/news/ health-26442420 (accessed March 2014).

145. Calefati J (2014) Health warning labels proposed for sodas, other sugary drinks sold in California. San Jose Mercury News, 13 February; available at http://www.mercurynews. com/california/ci_25137374/health-warning-labels-proposedsodas-other-sugary-drinks 